Engineering \& Technology | Roger Reed \& Yuanbo Tang

New superalloy design for 3D-printing set to transform manufacturing

Engineers at Alloyed, Professor Roger Reed, Dr Yuanbo Tang and colleagues at the University of Oxford, have developed new robust superalloys that can be used in additive manufacturing otherwise known as $3 D$ printing. Their 3 printed superalloy objects can be as strong as techniques, a breakthrough tha could transform the efficiency of some of our most complex manufacturing processes. rom jet engines through to the cores of power stations, much of
the advanced machinery that we the advanced machinery that we rely on can get hellishly hot. Within these
fiery spaces, fine control is required, and the components used to maintain this the components used to maintain this materials made of fantastically durable materials. Ohe such group of matenals materials are, unsurprisingly, difficult to manufacture and to manipulate into the precisely shaped components needed in advanced machines. Such production highly wasteful. Research carried out by Alloyed Ltd. with Professor Roger Reed and Dr Yuanbo Tang at the University of Oxford looks set to change that, by making it possible to $3 \mathrm{D}$ print superalloys directly into precision components.

The standard methods of manufacturing superalloy products have changed little, in principle, since the metalworking of poured into a silica mould and, once cooled, the finat shape is normally achieved by machining - scraping and iselling away parts of the moulded block. This is wasteful and timeconsuming; in fact, in standard form finished goods'.

\section{D PRINTING}

Additive manufacturing, or $3 \mathrm{D}$ printing, offers a modern and more efficient approach. It works by buld gin un an processes are lengthy, costly and can be about $10 \%$ of the superalloy ends up as to make very complex, precise shapes without wasting excess material. When 3D printing with alloys, each layer powder (containing grains of the severa compositional elements) which is then the togethr. This could nable the factory such as those used in jet engines that are currently produced through nefficient moulding and machining.

However, 3D printing using common superalloys, known as 'legacy' superalloys, has so far been unsuccessful. Excessive deformities and imperfections, including cracks and pores, appear in printed components throughout the printing process, component made this way.

\section{PIONEERING THE MANUFACTURE}

The chemical compositions of legacy sturdy object at the end of a lengthy process of moulding and cooling or else from a series of extensive thermomechanical working and machining which is radically different from the rapid heating and cooling that comes as a result of laser-melting. Indeed, as the laser fuses each layer to its surroundings in $3 \mathrm{D}$ printing, different parts of the newly-formed surface will exist simultaneously in all four states of matter (solid, liquid, vapour and temperature, between the molten layer being printed and the solidified down kac plack and distoyer is laid down, can crack and distort the fine is first added as a thin covering of compromising the strength of any plasma). The enormous gradients of layers below, and the rapid cooling resulting alloy its super properties. material is stacturing, where the rencer developing high-quality printed alloys.

A project led by Alloyed and funded by Innovate UK brought together researchers from Oxford University, including Dr Yuanbo Tang, Professor Roger Reed, Dr C. Panwisawas, McCartney, and engineers from Alloyed Ltd including Dr A. Nemeth, Dr J. Clark, and Dr D. Crudden. The team pioneered a new approach to printing. Rather than looking at ways pe printed, the team looked at designing would instead be optimised to gor through the additive manufacturing of traditionally machined legacy alloys.

\section{'ALLOYS-BY-DESIGN'}

The methodology used by the researchers to search for such alloys is called 'alloys-by-design' (ABD), a process of computational modelling pioneered by Professor Roger Reed at the University of Oxford. With their method, over ten million different

elemental

compositions

of alloy were

tested, exploring

the relationsh

material's manufacturing 'only about $10 \%$ of the superalloy ends up as finished goods." finditions and its material properties over which these properties were well-balanced. Materials with this composition were atoms in the material have forecast to have the desired qualities of The superalloy as well as being printable.

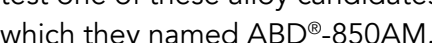

\section{TESTING}

To carry out these tests, the team new alloy, as well as blocks made of two long-established and widely-used legacy superalloys for comparison CM247LC and IN939.

The first test was a comparison of flaws . alloy blocks during manufacturing. optical microscope, optical microscope,
while the team also used a scanning to analyse the test one of trs went on to physically deed, it is this precarious stage of J. Ghoussoub and Professor D. panufacturng superalloys by $3 \mathrm{D}$ process and come out with the strength

microstructure of the matocks (the arranged together, for example in layers,

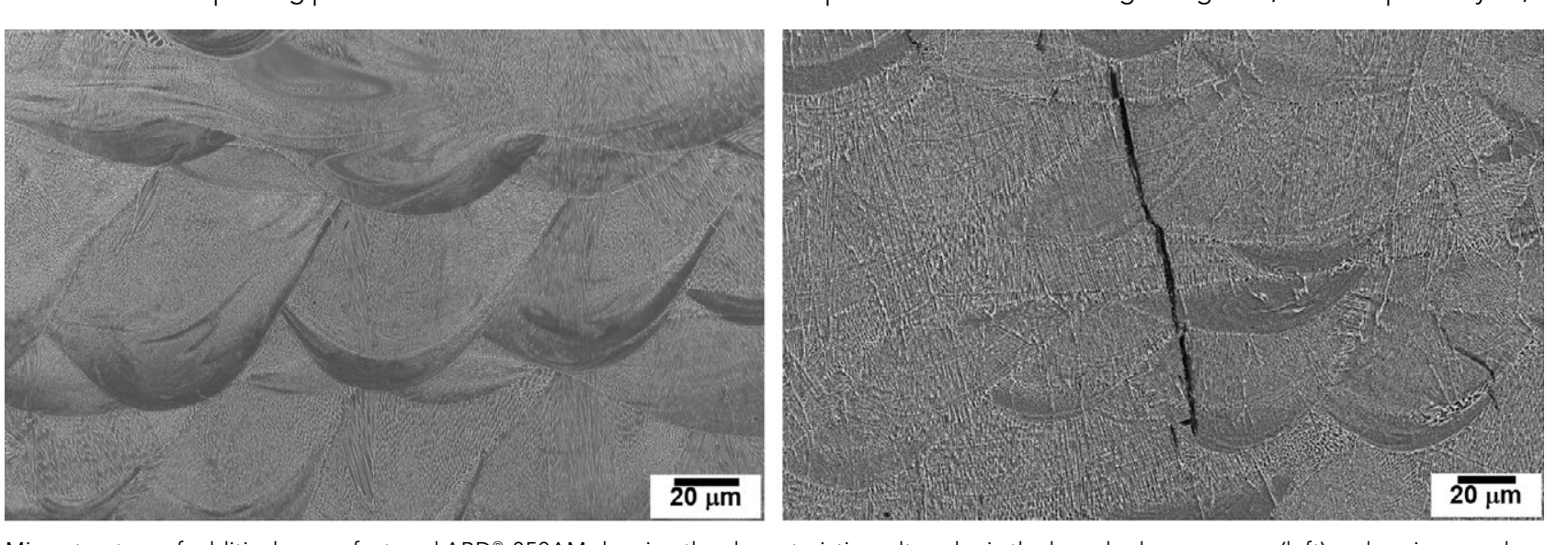

Microstructure of additively manutactured $A B D-850 A M$ showing the characteristic meltpol
that developed during the printing process in a legacy all loy (IN939) to relieve stresses (right) 

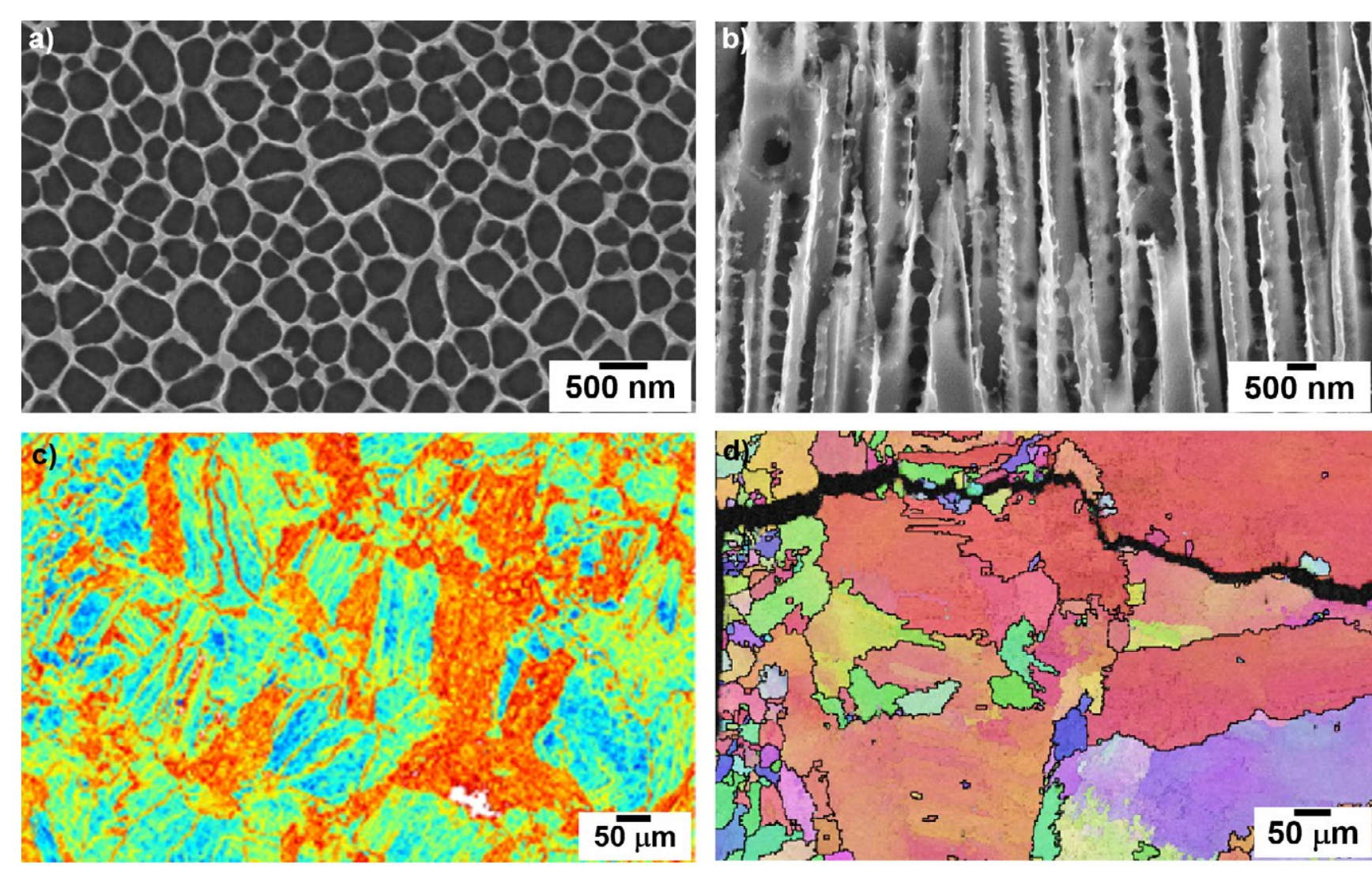

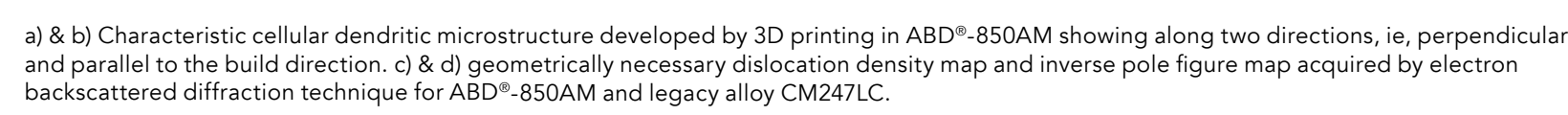

crystals, or grains, and gives an indication Using these results, they refined their of how the material will behave in extreme computer model used for the alloys-

optimised for additive manufacturing. or by-design process, and went on to

Through trialling blocks of this alloy, this These investigations

revealed that, as

expected, the

legacy alloy blocks

This technology paves the way for printed of the alloys had a strong effect $\begin{array}{cl}\text { components to be used in a variety of } & \begin{array}{l}\text { production possib } \\ \text { using additive } \\ \text { manufacturing }\end{array}\end{array}$ numerous cracks and flaws during the demanding, high-performance

(- test a second iteration of priable This

They then tested the performance of the three printed alloys when subjected to external forces at a range $1,000^{\circ} \mathrm{C}$. It was seen that printed blocks of $\mathrm{ABD}^{\oplus}$-850AM had similar performance to legacy superalloys until very hig temperatures towards $1,000^{\circ} \mathrm{C}$. The researchers believe that certain properties that optimise ABD-850AM for printing may cause it to perform less well under more extreme conditions. Specifically, the level of gamma-prime precipitates, which is a particular microstructure that gives nickel-based superalloys much of their strength, was lower in ABD a-bys
in the comparison legacy alloys. ABD-900AM. This alloy could also go through printing an come out with the exceptionally low but showed greater strength and creep resistance compared to the first generation superalloy $A B D^{\oplus}-850 A M$.

\section{NEW ALLOYS}

The production of precision shapes of high-quality alloy has traditionally been previous efforts to use $3 \mathrm{D}$ printing have resulted in alloys of unusably-low quality. The alloys-by-design approach used in this research has de monstrated a viable method to explore how the composition and was used to select an alloy that is an inefficient and wasteful process, while their designed alloy displased structural

flaws than the legacy oles after printing

Llikewise, their performance under the

strain tests demonstrated that these

performance required of superalloys.

high performance superalloys are

now printable.

The two new alloys, $\mathrm{ABD}^{\oplus}-850 \mathrm{AM}$ and $A B D^{\oplus}-900 A M$, are now manufactured by Alloyed's production partner Auber \& Duval, and sold internationally. legacy manufacturing of these nickelfor printed components to be used in a variety of demanding, hish- new alloys were capable of the high

As such, this team have proven that This technology promises to disrupt based superalloys, and paves the way

\section{Behind the Research}

4

Professor Roger C. Reed 0

Dr Yuanbo (Tony) Tang

E: yuanbo.tang@materials.ox.ac.uk

Research Objectives

The pioneering work of Alloyed Ltd, Roger Reed, and Yuanbo Tang addresses the issue that high performance superalloys are not printable, and is set to revolutionise the efficiency of some of the world's most complex manufacturing processes.

\section{Detail}

Address

Institute of Advanced Technology

University of Oxford

Begbroke Science Park

Oxfordshire OX5 1

Bio

Prof Roger C. Reed is a professor at the University of Oxford and also the Chief Scientific Officer of Alloyed Ltd. He is a world leader in designing and processing of high-temperature alloys. He is also a fellow of the Roya Academy of Engineering

Dr Yuanbo (Tony) Tang is a chartered engineer. He currently works as a research fellow at the University f advanced metallic systems, such as nickel-bance superalloys and bio-medical titanium alloys.

\section{Funding}

UK is much appreciated. We also thank Alloyed Ltd for materials provision.

Collaborators

Many engineers from Alloyed Ltd, especially Dr J. Clark, DrA. Nemeth, W. Dick-Cleland and Dr D. Crudden. We also thank other researchers in our research team in Oxford, including but not limited to DrC. Panwisawas, J. Ghoussoub, and Professor D. McCartney.

\section{Alloyed}

\section{References}

Tang, YT Panwisawas, C Ghoussoub, JN Gong, Y Clark, JWG Nemeth, AAN McCartney, DG Reed, RC (2021). Alloysby-design: Application to new superalloys for additive
manufacturing, Acta Materialia, 202, pp.417-436. https://doi. org/10.1016/j.actamat.2020.09.023 Tang, YT Ghoussoub, JN Panwisawas, C Collins, DM
Amirkhanlou, S Clark, JWG Németh, AAN McCartney, DG Reed, RC (2020). The Effect of Heat Treatment on Tensile Yielding Response of the New Suseralloy ABD-900AM for 2020. The Minerals, Metals \& Materials Series Springys, Cham. https://doi.org/10.1007/978-3-030-51834-9_103 Panwisawas, C Tang, YT and Reed, RC (2020). Metal 3D printing as a disruptive technology for superalloys. Nature Communication

Ghoussoub, JN Tang, YT Panwisawas, C Németh, A Reed, RC (2020). On the Influence of Alloy Chemistry and Processing Superalloys. In: Tin S. et al (eds) Superalloys 2020. The Minerals, Metals \& Materials Series. Springer, Cham. https:// doi.org/ $0.1007 / 978-3-030-51834-9-15$

Tang, YT Campbell, JE Burley, M Dean, J Reed, RC Clyne, TW (2021). Profilometry-based indentation plastometry to obtain
stress-strain curves from anisotropic superalloy made by additive manufacturing, Materialia, 15, https://doi. org/10.1016/j.mtla.2021.101017

\section{Personal Response}

\section{How do you think the adoption of additive} manufacturing will affect industries that rely on nickel-based superalloy components?

II The mind of designers is never exhausted, but it can be limited by the pragmatics of what is available. For example, the current component design in jet engines is With the adoption and thrive of additive manufacturing. enabled by the suitable superalloys designed dedicated to the technology, we envisage a vast change of the whole system design to come, where delicate internal structures can be developed and modified to better sheds light on the development of lightweight structures with improved thermal and fuel efficiency, and has particularly great potential for hypersonic aviation and
aerospace exploration. 